\title{
Public Enterprises and \\ Labor Market Performance
}

Johannes Hörner, L.Rachel Ngai and Claudia Olivetti

January 2004 


\begin{abstract}
This paper shows that state control of some industries may have contributed to the increase in European unemployment from the 1970s to the early 1990s. We develop a simple model with both publicly-run and privately-run enterprises and show that when economic turbulence increases, higher unemployment rates may result in economies that have a larger public sector.
\end{abstract}

JEL Classification: E240, J450, J640

Keywords: European Unemployment, Public Sector Employment

This paper was produced as part of the Centre's Technology and Growth programme.

The Centre for Economic Performance is financed by the Economic and Social Research Council

\title{
Acknowledgements
}

We are grateful to Christopher Pissarides, Richard Rogerson and Robert Shimer for many conversations and useful suggestions. We have benefited from comments of seminar participants at Boston College, Boston University, London School of Economics, CERGE, SED, NBER, EEA-ESEM and the Second Biennial Conference of Hong Kong Economic Association.

Johannes $\mathrm{H}$ rner is Assistant Professor of Managerial Economics and Decision Sciences at the Kellogg School of Manage ment, Northwestern University. L.Rachel Ngai is an Associate of the Centre for Economic Performance and a Lecturer in Economics, London School of Economics. Claudia Olivetti is Assistant Professor at Boston University's Department of Economics.

Published by

Centre for Economic Performance

London School of Economics and Political Science

Houghton Street

London WC2A $2 \mathrm{AE}$

All rights reserved. No part of this publication may be reproduced, stored in a retrieval system or transmitted in any form or by any means without the prior permission in writing of the publisher nor be issued to the public or circulated in any form other than that in which it is published.

Requests for permission to reproduce any article or part of the Working Paper should be sent to the editor at the above address.

(C) J. H`rner, L.Rachel Ngai and C. Olivetti, submitted 2004

ISBN 0753017113 


\section{Introduction}

In this paper, we focus on a neglected aspect of the economy in the explanation of the rise of European unemployment since the late 1970s; that of state control. We argue that state control of some sectors of the economy can contribute to the rise in aggregate unemployment when the economy is hit by increased turbulence, where "turbulence" is interpreted as the variability in the occurrence and strength of a variety of possible shocks to the world economy. The mechanism by which this takes place is the following. In an economy with two sectors, a private one that cannot fully insure workers against turbulence and a state one that can insure them, workers will prefer to wait for a job in the state sector, rather than accept a job immediately in the private sector. We show that this mechanism has as a consequence the fact that when the economy is hit by shocks with more variance, aggregate unemployment will be higher, on average, than in an economy where shocks have less variance. We follow Ljunqvist and Sargent (1998) in claiming that the European economy has been subjected to significant increases in turbulence since the late 1970s. According to our model, such increases in turbulence should lead to higher average unemployment in economies that have a larger public sector. We gather empirical evidence that supports this prediction.

The existing literature on the rise of European unemployment has focused mainly on the role of labor market institutions in explaining the European unemployment experience and its differences from that of the U.S. experience. ${ }^{1}$ Our methodology is similar to that of the works cited, to the extent that we focus on the interaction between the turbulence shock and the institution of public ownership, but we do not model other labor market institutions. ${ }^{2}$ Our work is more closely related to recent empirical work that considers the importance of regulation in product markets and of public ownership in explaining crosscountry differences in employment outcomes (Nicoletti, Scarpetta and Boylaud (2001)), and in private investment and growth (Alesina, Ardagna, Nicoletti, and Schiantarelli (2003)).

We develop a simple two-sector model that has risk-averse workers directing their search into one of the sectors. There is a fixed cost to creating a vacancy in each sector. In the benchmark economy, both sectors are private and firms are free to create vacancies. In the European economy, Sector 1 is a public sector and only the government can create

\footnotetext{
${ }^{1}$ See Bruno and Sachs (1985), Layard et al (1991), Phelphs (1994), Nickell (1997), Blanchard and Wolfers (2000).

${ }^{2}$ For other models along these lines, see Bentolila and Bertola (1990), Bertola and Ichino (1996), Bertola and Rogerson (1997), and Mortenson and Pissarides (1999a and 1999b) for mechanisms emphasizing demand side factors, and Marimon and Zilibotti (1999), and Ljunqvist and Sargent (1998) for supply side mechanisms.
} 
vacancies. In each sector, workers and vacancies are matched randomly. The output of a match is subject to match-specific productivity shocks. Workers and firms share ex post the output in a private match, but the wage is set by the government in the public sector. The key results in our model hinge on the following mechanisms: (1) the worker's choice of the sector in which to search for a job depends on both the expected volatility of wages offered and the probability of getting a job; (2) the government can provide more insurance against match-specific shocks than private firms; and (3) the government can influence the incentives that firms have to enter the private sector by influencing the number of job searchers who enter the public sector, for example, by opening up vacancies or increasing wages. We show that the presence of the public sector in the European economy may entail higher aggregate unemployment than in the benchmark economy. We investigate the implication of a mean-preserving spread of the match-specific shock in our economy. We find that in equilibrium there will be higher unemployment in the European economy following an increase in turbulence, because workers will be queueing for public sector jobs, which offer less risky wage profiles.

Our results are related to an older literature that studies how the presence of a unionized sector in the economy, which offers "safer" jobs, may generate high and persistent unemployment, because workers queue for such "protected" jobs. In our model the government plays a similar role to that played by the union in this literature (see the discussion in Hall (1975)). More recently, Rodrik (1997) has emphasized the role of the public sector as an insurance mechanism against household income and consumption risk in countries that face a relatively large and undiversifiable external risk.

Our model is complementary to recent papers that study the interaction of state and private ownership. Blanchard and Giavazzi (2003) develop a model that studies the interconnection between labor market institutions and the state's regulatory intervention on the production side of the economy. Our paper contributes to this literature by providing insights into one possible mechanism through which the presence of an active government in an economy may affect its labor market performance. Finally, Algan, Cahuc, and Zylberberg (2002) show that public employment crowds out total employment in those countries where goods produced in the public sector are substitutes for goods produced in the private sector. This finding is consistent with ours, because the goods produced by the two sectors are substitutes in the model.

The rest of the paper is organized as follows. Section 2 describes the model. Section 3 describes its principal implications. Finally, Section 4 presents some empirical evidence in favor of the mechanism that we describe. 


\section{Model}

We consider a two-sector economy that is populated by four types of agent: workers, capitalists, firms and a government. Each firm operates in one of the two sectors, 1 and 2, and produces respectively the only two consumption goods, 1 and 2. Firms are risk neutral, and have identical production technologies, each requiring exactly one unit of capital and one worker. The output of a firm is independently and identically distributed. In all sectors, capital is rent from capitalists at a fixed exogenous price. In our economy, which we term Europe, the two sectors differ with respect to their ownership: the first sector is public, while the second is private.

There are two differences between the public and private sectors. (1) In the private sector, a worker is paid an exogenous fraction of the output's value. In the public sector, his wage is set by the government. (2) In the private sector, the number, or mass, of firms is such that the expected profit is zero. In the public sector, the mass of firms is set by the government.

There is a unit mass of workers in the economy. Workers and firms that have rent capital meet simultaneously according to a matching technology that we assume is homogenous of degree one. The search is directed. Workers are risk-averse and choose whether, and where, to search to maximize their expected utility as consumers. In both sectors, unemployed workers, that is, workers that remain unmatched, are entitled to benefits set

by the government. Moreover, both labor and capital incomes, including unemployment benefits, are taxed at an identical rate fixed by the government. Net labor and capital income are spent by consumers (workers and capitalists) on the two goods. Prices clear the goods markets.

In the European economy, the government controls the unemployment benefits, the tax rate, the measure of public firms, the wage paid to its employees, and the price at which it sells its output. Its revenues consist of tax, and sales of Good 1, and its expenditures consist of capital expenditure as well as unemployment benefits and wages paid in the public sector.

We compare our European economy to a benchmark economy in which both sectors of production are private (we will also refer to the latter as to the "all-private" economy). Since Sector 1 is private in the benchmark economy, the government controls only the unemployment benefits and the tax rate: its revenues consist of tax, and its expenditures consist of unemployment benefits. Notice that we are comparing two economies that differ only in their ownership structure; their other fundamentals are identical.

We begin our analysis by solving for the equilibrium of the economy. The equilibrium 
for our European economy is a list of functions that satisfies the following conditions: (1) labor indifference; (2) goods market clearing; (3) the free entry condition for Sector 2, and (4) the government's budget is balanced. The labor indifference condition states that in equilibrium workers are indifferent between searching in either of the two sectors. The free entry condition states that the mass of private firms in the private sector (Sector 2) is such that expected profits are zero. An optimum is a subset of equilibria in which the expected utility level of the representative worker is maximized. A similar definition applies to the benchmark economy. However, in that case, there is one additional constraint that must be satisfied: the free entry condition must also hold for Sector 1 in the benchmark economy, because both sectors are privately run in this case.

In what follows we lay out the specification of the model and equilibrium conditions for the particular example developed in later sections. First, we analyze the equilibrium for the benchmark economy and for the European economy. Note that, for the latter, the set of government policies includes the measure of firms operating in the public sector, the wage paid in public sector jobs, and the relative price of Good 1. We emphasize how these additional tools that the government has in the public sector (Sector 1) affect the economy's employment performance, the share of public employment and the size of the private sector. Finally, in the second part of section 2.1 we turn to the analysis of the optimal government policy. A more general analysis of the optimum is carried out in the appendix, where we show that our results hold for a generic utility function $U: \mathbb{R}_{++}^{2} \rightarrow \mathbb{R}$ that is smooth, jointly strictly concave and strictly increasing in both terms. In the exposition we use superscript $B$ for the benchmark, "all private," economy, and superscript $E$ for Europe (the partially public economy). Subscript $i=1,2$ will refer to the corresponding good or sector.

\subsection{Model Specification and Equilibrium Conditions}

Let $u_{i}$ be the measure of workers searching in Sector $i$ and $v_{i}$ be the measure of vacancies posted in Sector $i$. Since there is a unit mass of workers in the economy it follows that $u_{1}+u_{2} \leqq 1$. This condition will hold with equality if all workers search for a job. The number of matches in Sector $i$ is determined by a matching function, $M_{i}=M\left(u_{i}, v_{i}\right)$, which is increasing in both $u$ and $v$, concave and homogeneous of degree one. We assume the matching function to be identical across sectors and, following the literature in this area, we use a Cobb-Douglas specification, that is: $M_{i}=A u_{i}^{\gamma} v_{i}^{1-\gamma}$ where $\gamma \in(0,1)$ and $A$ is a scale parameter that is positive and small enough to guarantee that the probabilities of being matched, both for workers and for firms, are between zero and 1 . We denote the probability that a worker searching in Sector $i$ gets a job by $\phi\left(\theta_{i}\right) \equiv \frac{M\left(u_{i}, v_{i}\right)}{u_{i}}=A \theta_{i}^{1-\gamma}$ where 
we denote by $\theta_{i} \equiv \frac{v_{i}}{u_{i}}$ the market tightness in Sector $i$. The measure of total employment in each economy is denoted by $E=M_{1}+M_{2}$.

The output of a match is subject to an idiosyncratic shock that is i.i.d. both across firms and across sectors. We assume that the (random) output of a match $Y$ is distributed according to a lognormal distribution, that is, $Y=e^{z}$ where $z \sim N\left(\lambda, \sigma^{2}\right)$. Hence, the total output in Sector $i=1,2$ is simply given by $M_{i} y$, where $y=E\left[e^{z}\right]=\exp \left(\lambda+\sigma^{2} / 2\right)$ is the expected output of a firm.

The wage paid to a worker is denoted by $w_{j}$, where the subscript $j=0,1,2$ refers to the worker's status. A worker receives wage $w_{0}$ if unemployed, and wage $w_{1}$ and $w_{2}$ if he works in Sector 1 or 2 , respectively. In the public sector workers are paid a constant wage. In the private sector workers are paid a share $\alpha \in(0,1)$ of the realized output, that is, the private sector wage is risky.

Consumers consists of workers and capitalists. The income of the capitalists is given by the total payment made by firms in both sectors. That is, their income is given by $R\left(v_{1}+v_{2}\right)$ where $R$ is the cost of opening a vacancy. We assume that both types of consumer are characterized by the same preferences over consumption. We assume a constant relative risk aversion utility function with a unitary elasticity of substitution between the two goods. Hence, the consumer's problem is to maximize

$$
U\left(c_{1}, c_{2}\right)=\frac{\left(c_{1}^{\beta} c_{2}^{1-\beta}\right)^{1-r}-1}{1-r},
$$

by choosing $\left(c_{1}, c_{2}\right)$ subject to

$$
p c_{1}+c_{2} \leq(1-\tau) \omega,
$$

where $c_{i}, i=1,2$ is the quantity of Good $i$ he consumes, $\tau$ is the proportional tax rate, $p$ is the relative price of Good 1 with respect to Good 2 , and $\omega$ is a consumer's gross income ( $\omega=w_{j} j=0,1,2$ for workers, and $\omega=R\left(v_{1}+v_{2}\right)$ for capitalists). The parameter $\beta$ belongs to the open unit interval, and $r \geq 0$ represents the coefficient of risk aversion (note that for $r=1$ the utility function reduces to $\left.\ln \left(c_{1}^{\beta} c_{2}^{1-\beta}\right)\right)$. Under this specification the Walrasian demand functions, $c_{i}((1-\tau) \omega, p)$ for $i=1,2$, are linear for consumers' income. We denote the corresponding indirect utility function by $V((1-\tau) \omega, p)$.

In equilibrium both markets clear, that is for $i=1,2$ :

$$
\begin{aligned}
M_{i} p_{i} y= & M_{1} E\left[c_{i}\left((1-\tau) w_{1}, p\right)\right]+M_{2} E c_{i}\left(w_{2}(1-\tau), p\right)+ \\
& \left(1-M_{1}-M_{2}\right) E\left[c_{i}\left((1-\tau) w_{0}, p\right)\right]+c_{i}\left((1-\tau) R\left(v_{1}+v_{2}\right), p\right)
\end{aligned}
$$


We now turn to the workers' search decision. In our model there are two sources of uncertainty in the worker's choice of the sector in which to search for a job. That is, he faces both employment risk, in that he may or may not find a job, and "wage" risk, since in the private sector he will be paid a share $\alpha$ of the realized output. Hence, his choice depends on both the wage offered and the probability of getting a job in each sector. A worker will search for a job in Sector 1 if and only if the expected utility in Sector 1 is larger than in Sector 2, that is if and only if $E U_{1} \geq E U_{2}$ where:

$$
E U_{i}=\phi_{i}\left(\theta_{i}\right) E V\left((1-\tau) w_{i}, p\right)+\left(1-\phi_{i}\left(\theta_{i}\right)\right) V\left((1-\tau) w_{0}, p\right) \quad i=1,2 .
$$

In equilibrium, all workers search for a job and are indifferent between searching in either sector. This gives us our second equilibrium condition, which we will define as labor indifference (hereafter, LI):

$$
E U_{1}=E U_{2} \geq V((1-\tau) b, p)
$$

The measure of firms in the private sector is determined by free entry; that is, firms will enter up to the point at which the expected profit of an additional vacancy is equal to zero. In particular, the free entry condition (hereafter, $F E$ ) pins down the market tightness in each (private sector) $i$, that is:

$$
\phi\left(\theta_{i}\right) \theta_{i}^{-1}(1-\alpha) p_{i} y=R
$$

where $p_{1}=p, p_{2}=1$. This condition needs to hold in Sector 2 for the European economy, and must also be satisfied in Sector 1 in the benchmark economy.

Finally, the government must balance its budget. The budget-balanced condition for the benchmark economy is given by:

$$
\tau\left\{\left(p M_{1}+M_{2}\right) \alpha y+R\left(v_{1}+v_{2}\right)\right\}=(1-\tau) w_{0}\left(1-M_{1}-M_{2}\right)
$$

where government revenues come from (proportional) income taxes on labor and capital income and its expenditures consist of unemployment benefits. However, in the European economy the government collects additional revenue from the sale of the good it produces (Good 1) and faces additional costs, namely the cost of labor $w_{1}$ and the cost of opening public sector vacancies $R v_{1}$. Hence, the budget-balanced condition for Europe is given by:

$$
\tau\left(M_{2} \alpha y+R v_{2}\right)+M_{1} p Y=(1-\tau)\left[\left(1-M_{1}-M_{2}\right) w_{0}+R v_{1}+M_{1} w_{1}\right] .
$$

Before solving the model, let us emphasize its key assumptions. First, the matching technology is homogeneous of degree one. Second, both the matching and the production 
technologies are the same across sectors. Because of these two assumptions, comparing unemployment rates across economies reduces to comparing the market tightness between a publicly-run sector and a privately-run one.

We further assume, in our analysis of the optimum, that the government maximizes the representative worker's expected utility, not the capitalist's. This assumption entails that the government bears a real cost when it opens a vacancy, because the rental fee is paid to the capitalists, not the workers. ${ }^{3}$ However, creating a vacancy in the public sector generates revenue for the government; namely, the value of the output that it generates. Therefore, the government faces a familiar trade-off when deciding how many public vacancies to post. ${ }^{4}$

\subsection{Solving the model}

\subsubsection{Equilibrium Analysis}

In the benchmark economy, the market tightness in each sector is determined by free entry. Since, by free entry, firms are indifferent between opening a vacancy in either sector, and workers must be indifferent between searching in either sector, it follows that the equilibrium price must be one. This follows from the following Lemma. Define $\theta^{B}:=[A(1-\alpha) y / R]^{1 / \gamma}$.

Lemma 1 In any equilibrium, $\theta_{1}^{B}=\theta_{2}^{B}=\theta^{B}, p^{B}=1$.

Proof: Free entry in both sectors implies that:

$$
p^{B} \frac{\phi\left(\theta_{1}^{B}\right)}{\theta_{1}^{B}}=\frac{\phi\left(\theta_{2}^{B}\right)}{\theta_{2}^{B}} .
$$

Since workers are indifferent across sectors, $\forall w_{0}$,

$$
\begin{aligned}
& \phi\left(\theta_{1}^{B}\right)\left[\mathbf{E}\left[V\left((1-\tau) \alpha p^{B} Y, p^{B}\right)\right]-V\left((1-\tau) w_{0}, p^{B}\right)\right] \\
= & \phi\left(\theta_{2}^{B}\right)\left[\mathbf{E}\left[V\left((1-\tau) \alpha Y, p^{B}\right)\right]-V\left((1-\tau) w_{0}, p^{B}\right)\right],
\end{aligned}
$$

where $V(w, p)$ is the consumer's indirect utility function, given income $w$ and price $p$, and $\mathbf{E}[\cdot]$ denotes the expectation operator. It follows from this labor indifference condition, $L I$, that $p^{B}=1$. Indeed, suppose for the sake of contradiction that $\theta_{2}^{B}>\theta_{1}^{B}$. Since $\phi(\theta) / \theta$ is decreasing in $\theta$, it follows that $p^{B}<1$, which implies that:

$\mathbf{E}\left[V\left((1-\tau) \alpha p^{B} Y, p^{B}\right)\right]-V\left((1-\tau) w_{0}, p^{B}\right)<\mathbf{E}\left[V\left((1-\tau) \alpha Y, p^{B}\right)\right]-V\left((1-\tau) w_{0}, p^{B}\right)$.

\footnotetext{
${ }^{3}$ If this were not the case, the government would choose an infinite measure of public firms.

${ }^{4}$ It is also worth mentioning here that, by construction, the welfare in the European economy is always larger than in the benchmark economy. Obviously, we do not view this as a compelling description of reality, as our model ignores several other aspects of public management (incentives, information processing, etc).
} 
Since $\phi(\theta)$ is increasing in $\theta$, this contradicts LI. Assuming $\theta_{2}^{B}<\theta_{1}^{B}$ leads to a similar contradiction. Therefore, $\theta_{2}^{B}=\theta_{1}^{B}$ and thus $p^{B}=1$. From free entry, we obtain that $\theta_{i}^{B}=[A(1-\beta) y / R]^{1 / \gamma}$

In the European economy, the public sector offers three control variables to the government. First, the government chooses the price $p^{E}$ at which to sell its output. Second, it chooses the wage $w_{1}^{E}$ that it pays its workforce. Third, it chooses the "size" $v_{1}^{E}$ of the public sector. ${ }^{5}$ Fixing two out of these three variables, it is possible to investigate how variations in the third affect the equilibrium employment in Europe, $E^{E}=M_{1}^{E}+M_{2}^{E}$, the size of the private sector $v_{2}^{E}$, and the two measures of the relative size of the public sector, $M_{1}^{E} /\left(M_{1}^{E}+M_{2}^{E}\right)$ and $v_{1}^{E} /\left(v_{1}^{E}+v_{2}^{E}\right)$. The results are summarized in the following Lemma.

Lemma 2 In any equilibrium:

1. An increase in $v_{1}^{E}$ (holding $w_{1}^{E}$ and $p^{E}$ fixed) leads to an increase in $E^{E}$, an increase in $v_{2}^{E}$, an increase in $v_{1}^{E} /\left(v_{1}^{E}+v_{2}^{E}\right)$, and leaves $M_{1}^{E} /\left(M_{1}^{E}+M_{2}^{E}\right)$ unchanged.

2. An increase in $w_{1}^{E}$ (holding $v_{1}^{E}$ and $p^{E}$ fixed) leaves $E^{E}, v_{2}^{E}, v_{1}^{E} /\left(v_{1}^{E}+v_{2}^{E}\right)$ and $M_{1}^{E} /\left(M_{1}^{E}+M_{2}^{E}\right)$ unchanged.

3. An increase in $p^{E}$ (holding $v_{1}^{E}$ and $w_{1}^{E}$ fixed) leads to a decrease in $E^{E}$ if and only if $A$ is small enough. It leads to an increase in $v_{2}^{E}$, and to a decrease of both $v_{1}^{E} /\left(v_{1}^{E}+v_{2}^{E}\right)$ and $M_{1}^{E} /\left(M_{1}^{E}+M_{2}^{E}\right)$.

Proof: It follows from free entry that, in equilibrium, $\theta_{2}^{E}=\theta^{B}$. It follows from market clearing that:

$$
p^{E}=\frac{\beta \phi\left(\theta^{B}\right)}{1-\beta} \frac{1-u_{1}^{E}}{\phi\left(\theta_{1}^{E}\right) u_{1}^{E}} .
$$

Employment is given by:

$$
\begin{aligned}
E^{E} & =\left(1-u_{1}^{E}\right) \phi\left(\theta^{B}\right)+u_{1}^{E} \phi\left(\theta_{1}^{E}\right) \\
& =\left(1-u_{1}^{E}\right) \phi\left(\theta^{B}\right)\left[1+\frac{\beta / p^{E}}{1-\beta}\right] .
\end{aligned}
$$

The same substitution gives:

$$
\frac{M_{1}^{E}}{M_{1}^{E}+M_{2}^{E}}=\frac{1}{1+\frac{1-\beta}{\beta} p^{E}} \text { and } \frac{v_{1}^{E}}{v_{1}^{E}+v_{2}^{E}}=\frac{1}{1+\phi\left(\theta^{B}\right) \frac{1-u_{1}^{E}}{u_{1}^{E}}} .
$$

\footnotetext{
${ }^{5}$ The government also chooses the !!level!! of unemployment benefits, $w_{0}^{E}$, and the tax rate, $\tau^{E}$. However, (i) these choice variables are not directly related to the first sector ownership structure per se, (ii) they are also choice variables in the benchmark economy, and (iii) in equilibrium there are two constraints, labor indifference and budget balance that determine these levels, given $\left(v_{1}^{E}, w_{1}^{E}, p^{E}\right)$.
} 
All the conclusions are immediate from these expressions, with the exceptions of the effect of an increase in $p^{E}$ on $E^{E}$, and the effect of $v_{1}^{E}$ on $v_{1}^{E} /\left(v_{1}^{E}+v_{2}^{E}\right)$. These results follow from implicit differentiation of the corresponding equations

To summarize, increasing the number of vacancies in the public sector increases employment: since the price is fixed, so is the output ratio, and an increase in the size of the public sector thus also leads to an increase in the number of vacancies in the private sector. In turn, this leads to high output, and thus employment, in the economy. Similarly, as the price and thus the output ratio is fixed, varying the wage offered by the public sector has no impact on employment. Instead, it leads to an adjustment of unemployment benefit, in order to preserve the equal desirability of both sectors to the job searcher. The effect of price variations is more complex.

\subsubsection{Optimum Analysis}

Since the government is risk-neutral and the workers are risk-averse, it is not surprising that, at any optimum, the government provides full insurance against unemployment risk in the benchmark case as well as in the European case. That is, unemployment benefits equal the certainty equivalent of the (random) wage in the private sector. Moreover, the wage paid in the public sector, $w_{1}^{E}$ is also optimally set equal to this certainty equivalent, as follows from the indifference of workers across sectors, given the full insurance result. As these results hold in a more general environment, we refer the reader to the proof provided in the appendix for the latter case, and simply record them in the following Lemma.

Lemma 3 Given $\tau<1$ and $p>0$, define $w$ as the unique solution of:

$$
V((1-\tau) w, p)=\mathbb{E}[V((1-\tau) \alpha Y, p)] .
$$

Then, at any optimum, $w_{0}^{B}=w$, and $w_{0}^{E}=w_{1}^{E}=w$ given the corresponding values of $\tau$ and $p$.

Proof: See the appendix.

It is now straightforward to provide a complete characterization of the optimal solution to the benchmark economy.

Lemma 4 In the benchmark economy, the optimal solution is given by:

$$
\begin{gathered}
\theta_{1}^{B}=\theta_{2}^{B}=\theta^{B}, p^{B}=1, \\
u_{1}^{B}=\beta, \tau^{B}=\frac{\left(1-\phi\left(\theta^{B}\right)\right) w}{\left(1-\phi\left(\theta^{B}\right)\right) w+\phi\left(\theta^{B}\right) y}
\end{gathered}
$$


Proof: Since $p^{B}=1$, and market clearing requires:

$$
\frac{p^{B} M_{1}^{B}}{M_{2}^{B}}=\frac{\beta}{1-\beta},
$$

it follows that $u_{1}^{B}=\beta$ and $v_{1}^{B}=\theta^{B} \beta$. Finally, budget balance requires:

$$
\left(1-\phi\left(\theta^{B}\right)\right)\left(1-\tau^{B}\right) w_{0}^{B}=\tau^{B} \phi\left(\theta^{B}\right) y .
$$

Solving for $\tau^{B}$ gives the explicit expression for the proportional tax rate.

It is a little more tedious to derive the optimal solution for the European economy, as the European government is free to choose $v_{1}^{E}$ and $p$ in such a way as to maximize the agents' expected utility. Nevertheless, the following Lemma, along with the previous Lemmas, provides a complete characterization of the European optimum.

Lemma 5 In the European economy, the optimal solution is given by:

$$
\begin{aligned}
\theta_{1}^{E} & =\frac{(1-\gamma) w}{\gamma R}, u_{1}^{E}=\frac{\beta \gamma\left[1-\phi\left(\theta^{B}\right)+\phi\left(\theta^{B}\right) y / w\right]}{(1-\beta)+\beta \gamma\left[1-\phi\left(\theta^{B}\right)+\phi\left(\theta^{B}\right) y / w\right]}, \\
p^{E} & =\frac{\phi\left(\theta^{B}\right)}{\phi\left(\theta_{1}^{E}\right) \gamma\left(1-\phi\left(\theta^{B}\right)+\phi\left(\theta^{B}\right) y / w\right)} \text { and } \tau^{E}=\frac{1-\phi\left(\theta^{B}\right)}{1-\phi\left(\theta^{P}\right)+\phi\left(\theta^{B}\right) y / w} .
\end{aligned}
$$

Proof: Taking $\tau^{E}$ and $v_{1}^{E}$ as given, we can solve for all the other variables from labor indifference, market clearing, free entry and budget balance. Indeed, defining:

$$
f:=\phi\left(\theta^{B}\right)\left(\frac{\beta}{1-\beta} y+\tau y+(1-\tau) w\right)
$$

we obtain (omitting superscripts):

$$
\begin{gathered}
p=\frac{\beta}{1-\beta} \frac{(1-\tau)\left(w+R v_{1}\right) f^{\gamma-1}}{v_{1}^{1-\gamma}\left[f-(1-\tau)\left(w+R v_{1}\right)\right]^{\gamma}}, \\
u_{2}=\frac{(1-\tau)\left(w+R v_{1}\right)}{f}, u_{1}=1-u_{2}, v_{2}=\theta^{B} u_{2} .
\end{gathered}
$$

We then maximize the indirect utility function with respect to $\tau^{E}$ and $v_{1}^{E}$, that is, given that $w_{0}^{E}=w_{1}^{E}=w$, we solve:

$$
\max _{\tau, v}(1-\tau) p^{-\beta}
$$

given the expression found for $p$. The results follow from the first-order conditions. The second-order conditions are easily verified 
Observe that $\theta_{1}=\frac{1-\gamma}{\gamma} \frac{w}{R}$ is the optimal ratio $v_{1} / u_{1}$ that a firm maximizing $p M_{1} y-$ $(1-\tau) w u_{1}-(1-\tau) R v_{1}$ would choose. One way to explain this fact is as follows. The budget surplus can be split into two parts, as follows

$$
\begin{aligned}
& {\left[p M_{1} y-(1-\tau) w u_{1}-(1-\tau) R v_{1}\right]+\left[\tau M_{2} y-(1-\tau) w\left(u_{2}-M_{2}\right)\right], \text { or }} \\
& {\left[A p y \theta_{1}^{1-\gamma} u_{1}-(1-\tau) R \theta_{1} u_{1}-(1-\tau) w u_{1}\right]+\left[\tau y \theta_{2}^{1-\gamma} u_{2}-(1-\tau) w\left(u_{2}-u_{2} A \theta_{2}^{1-\gamma}\right)\right] .}
\end{aligned}
$$

which clearly distinguishes between revenues and expenditures by sector. For a fixed price, the marginal budget surplus of a worker in each sector must be zero, for otherwise, by holding fixed $\theta_{i}, i=1,2$, but increasing $u_{i}$ in the sector $i$ for which this marginal surplus is positive, the government could increase its surplus while preserving the consumers' utility, a contradiction. As the second formulation emphasizes, however, each sector's surplus is linear in $u_{i}$, so that marginal surplus equals average surplus, each term is zero, and the optimal $\theta_{1}$ can then be determined by examining only $p M_{1} y-(1-\tau) w u_{1}-(1-\tau) R v_{1}$. Using this perspective, we can represent the determination of market tightness in Figure 2.1, where $T R$ and $T C$ (resp. $M R$ and $M C$ ) denote total (resp. marginal) revenue and cost, and subscripts $F$ and $G$ refer to the private firms and the government-managed firms, respectively. The figure is drawn for the case in which employment in the public Sector 1 is smaller than employment in the corresponding private sector in the benchmark economy. However, the opposite case may occur for a different set of parameter values. The next session discusses the model's predictions.

\section{Discussion}

Our model yields two important results. First, we show that the comparison of unemployment rates in the partially public economy and in the all-private economy may go either way, depending on the parameters. Second, our model predicts higher unemployment in the European economy following a mean-preserving spread in the distribution of idiosyncratic shock.

With respect to the first point, consider the effect of ownership structure on the aggregate employment rate. The aggregate employment rate in our model is a weighted average of the probabilities of finding a job in the two sectors, $E=u_{1} \phi\left(\theta_{1}\right)+\left(1-u_{1}\right) \phi\left(\theta_{2}\right)$. One pleasing feature of the model is that the comparison of aggregate employment rates between the benchmark economy and the European economy reduces to comparing the labor market tightness in the public sector relative to the corresponding object in the private sector. In fact, the results obtained in Lemma 1 and Lemma 4 imply that the labor market tightness 
in the benchmark economy is the same across sectors and it is also equal to the private sector labor market tightness in the European economy. As a consequence, the difference between the aggregate employment rate in the benchmark economy relative to the European economy reduces to:

$$
E^{B}-E^{E}=u_{1}^{E}\left(\phi\left(\theta^{B}\right)-\phi\left(\theta_{1}^{E}\right)\right) .
$$

Moreover, given the closed form solution for our model described in Lemmas 4 and 5, we find that the difference between the private and the public labor market tightness is proportional to:

$$
\theta^{B}-\theta_{1}^{E} \fallingdotseq\left(\frac{1-\alpha}{\alpha}\right)\left(\frac{\alpha y}{w}\right) \phi_{B}-\frac{1-\gamma}{\gamma}
$$

where $\phi_{B}<1$ is the probability that a worker finds a job in the private sector,which is also the aggregate employment rate in the benchmark economy. A simple way to look at this expression is to consider the case in which the workers' share in the private sector $\alpha$ is equivalent to their share in the matching function, i.e. $\alpha=\gamma$. In this case the benchmark economy has a higher unemployment rate than the European economy if workers are riskneutral, i.e. if the certainty equivalent $w=\alpha y$. However, if workers are sufficiently riskaverse, that is if $w$ is small enough, this inequality is reversed. This is due to the fact that risk-averse workers are more willing to search in the public sector, which offers insurance against wage risk.

In general, the parameters $\alpha, \gamma$, the vacancy $\operatorname{cost} R$ and the degree of risk aversion $r$ all determine the level of the private and public labor market tightness and, hence, are important determinants of their comparison. For example, decreasing $\alpha$ reduces public sector tightness but increases private sector tightness. In our model, the government faces a trade-off between the (sunk) real cost and the (social) benefit of opening vacancies in the state-controlled sector, where the social benefit corresponds to consumers' welfare. Hence, the lower the output share of the workers, the lower the benefit to the government for a given measure of public vacancies. This entails that the labor market tightness in the public sector and, therefore, employment in the European economy, is smaller as $\alpha$ is lower. By contrast, labor market tightness in the private sector is determined by the free entry condition. The expected profit of opening a vacancy is higher, given the measure of job searchers, when the workers' share is lower. Thus, the private sector tightness decreases in $\alpha$. As a consequence, a lower $\alpha$ may result in a lower market tightness in Sector 1 in Europe with respect to the same sector in the benchmark economy and therefore, in lower total employment in the European economy relative to the benchmark economy. The parameter $\alpha$ may be interpreted as the worker's "bargaining" power. Our result may, at first sight, seem counterintuitive, because it is commonly thought that, given high unionization, an 
economy partially run by the government would have lower unemployment than an economy with private ownership. However, that widely held view presumes that economies with large public sectors also have a larger degree of unionization. In our model, the presumption does not hold, because in our comparison $\alpha$ is the same for the two economies.

The second point to be noted is that an important prediction delivered by our model relates to the effect of an increase in economic turbulence on unemployment in the European economy. We model the increase in turbulence as a mean-preserving spread of the distribution of output. The mean-preserving spread decreases the certainty equivalent $w$ of the private wage while leaving the expected output $y$ unchanged. European employment can be expressed as $E^{E}=\phi_{B}+u_{1}^{E}\left(\phi\left(\theta_{1}^{E}\right)-\phi_{B}\right)$. Since the mean-preserving spread does not affect expected output, the probability of finding a job in the private sector $\left(\phi_{B}\right)$, and hence private sector tightness, remains unchanged. By contrast, the public sector tightness decreases, due to two effects of the turbulence: (i) more workers are induced to search for a job in the public sector, which offers security by providing a constant wage profile, and (ii) fewer jobs are available in the public sector, because the government chooses to create fewer vacancies. ${ }^{6}$

Our model predicts an increase in both overall unemployment and, interestingly, public employment after a mean-preserving spread when either one of the following conditions holds before the spread: (1) if the public sector tightness is smaller than the private sector tightness, and there is a sufficiently small fraction of workers searching for a public job, i.e. if $1-\tilde{u}_{1}^{E}>(1-\gamma)\left(1+\frac{\left(1-\phi_{B}\right) \tilde{w}}{\phi_{B} y}\right)$,or $(2)$ if the public sector tightness is larger than the private sector tightness, and the fraction of workers searching for public jobs satisfies $1<\frac{1-\tilde{u}_{1}^{E}}{1-\gamma}\left(\frac{\phi_{B} y}{\phi_{B} y+\left(1-\phi_{B}\right) \tilde{w}}\right)<\frac{\phi\left(\theta_{1}^{E}\right)}{\phi\left(\tilde{\theta}_{1}^{E}\right)-\phi_{B}}$, where ' 'is used to denote variables before the meanpreserving spread.

Finally, it is interesting to note that following the mean-preserving spread, employment remains the same in the benchmark economy. Hence, even if initially the unemployment rate in the European economy is lower than in the benchmark economy, a large increase in turbulence may reverse the ranking of unemployment rates.

It is also interesting to examine whether our result is related to the standard efficiency results in search models (Hosios 1990). In a one-sector model, we know that if wages are too high $(\alpha>\gamma)$, there will be too little job creation and hence too much unemployment. So in a one-sector model, public ownership can give rise to either greater or less unemployment, depending on the wage level in the decentralized economy. In order to check whether the

\footnotetext{
${ }^{6}$ See the closed form solution for our model presented in Lemma 5.
} 
Hosios condition holds in the two-sector model, consider the social planner's problem, which is to maximize $U\left(c_{1}, c_{2}\right)$ by choosing $\left(u_{1}, \theta_{1}, \theta_{2}\right)$ subject to the resource constraints that the consumption of each good is equal to the difference of the total production and the total cost of creating vacancies, i.e. $c_{i}=u_{i}\left[\phi\left(\theta_{1}\right) y-R \theta_{i}\right], i=1,2$. The corresponding optimal conditions are:

$$
\begin{array}{rll}
\left(u_{1}\right) & : & U_{c_{1}}\left[\phi\left(\theta_{1}\right) y-R \theta_{1}\right]-U_{c_{2}}\left[\phi\left(\theta_{2}\right) y-R \theta_{2}\right]=0 \\
\left(\theta_{i}\right) & : & u_{i} U_{c_{i}}\left[(1-\gamma) \theta_{i}^{-1} \phi\left(\theta_{i}\right) y-R\right]=0 \quad i=1,2
\end{array}
$$

Thus, the social planner sets the same labor market tightness for both sectors equal to $\theta^{*}$, where:

$$
(1-\gamma) q\left(\theta^{*}\right) y=R
$$

which is the same as the free entry condition when $\alpha=\gamma$, that is, the labor market tightness is the same across sectors and is equal to the corresponding value in the all-private economy. Moreover, the optimal fraction of job searchers in Sector $1, u_{1}^{*}=\beta$, which is also the same as in the all-private economy. Therefore, the Hosios condition holds in the two-sector model as well. Note that the equilibrium for the partially-public (European) economy is different from the planner's solution, because the government controls only one sector of the economy.

\section{Empirical Evidence}

We now turn to the provision of empirical evidence in support of our theory. We begin by motivating our modeling choices. In particular, we show how public employment is quantitatively important in many countries and we document the increase in economic turbulence over the period of interest. Then, we show that our model's prediction is consistent with the observation that those European countries that experienced the largest increases in unemployment rates during the 1980s also experienced the largest increases in public employment. In addition, we document the fact that countries characterized by a larger presence of government in the economy tended to have lower employment rates and to exhibit lower employment growth during the 1980s. Finally, we provide evidence in favor of the theoretical finding that public sector workers are offered the certainty equivalent of the distribution of output. This is clearly an extreme case. The way to interpret this result is in terms of a relative larger volatility of the private sector wage distribution. Empirical studies show how the distribution of wages in the public sector is more compressed than in 
the private sector in many countries and how this differential grew during the 1980s and early 1990s.

We use a complete definition of the public sector that includes both publicly operated enterprises, and typical public sector activities, such as the provision of education, health services, public security, and administrative services. Public enterprises are governmentowned or -controlled economic entities that generate most of their revenue by selling goods and services. Other public sector activities, such as education, and health services, are mostly financed from the government's general revenue. In many European countries, the government has a presence in commercial, industrial, and financial sectors of the economies including banking, car manufacturing, airlines, telecommunications, postal services, oil extraction, refinement and distribution. The government operates such enterprises either by controlling these firms directly or by holding a majority of their shares.

As a consequence of this large and diverse set of public sector activities it is very difficult to find an inclusive and comparable cross-country measure of public employment. Countries differ in the structure of their government and degree of centralization, in their accounting procedures and so forth. We use data from a 1997 OECD report to show how large is the public sector and what is its variation across countries. To our knowledge this report provides the best available data on employment in the public sector. Moreover, it includes employment in public enterprises. ${ }^{7}$ Table 4.1 summarizes data on employment in the limited public sector and in public enterprises as a fraction of total employment. The limited public sector includes ministries and other services of (central and local) government, education, health, and the army, as well as other activities that are financed primarily by the government's general revenue. The first column shows how the size of the limited public sector is quite relevant and how it varies across countries. The limited public sector accounts for around $20 \%$ of total employment in Italy and France. In the United States, government employment accounts for around $14 \%$ of total employment. Scandinavian countries have the largest governments, which account for more than $30 \%$ of total employment in both Sweden and Denmark. The role of the government in the production sector also differs quite substantially across countries. Entries in the second column of Table 4.1 represent the share of employment in public enterprises relative to total employment. This share is almost negligible in the United States $(0.7 \%)$ and Japan (0.5\%), whereas it is a quantitatively relevant part of total employment (above 4\%) for many European countries. When we

\footnotetext{
${ }^{7}$ See the report "Measuring Public Employment in OECD countries: Sources, Methods, and Results" (1997) for a detailed discussion of the national data sources. Data for different countries are available for different years between 1993 and 1996.
} 
consider both components of public employment, the share of total employment due to government employment ranges from $7 \%$ in Japan to more than $20 \%$ in many European countries, including Italy (23.2\%), France (27\%) and the Scandinavian countries, where the public sector constitutes $40 \%$ of total employment.

A second way to document the importance of government control over some sectors of the economy is to use the indicator of state involvement in the economy developed by Nicoletti, Scarpetta and Boylaud (1999). This indicator is a component of a set of indexes of product market regulation that have recently stimulated a number of papers (see, for example, Alesina, Ardagna, Nicoletti and Schiantarelli (2003), Blanchard and Giavazzi (2003), Blanchard and Philippon (2003), and Ebell and Haefke (2002)). Figure 4.1 plots the index of state ownership for the subset of twenty countries considered in Table 4.1. This index, which ranges between 1 and 6 , is based on summary indexes of the scope and size of public enterprises in the economy. ${ }^{8}$ This graph offers a clear snapshot of crosscountry differences in public ownership in the late 1990s and shows that the extent of public ownership in the economy is of relevance in many European countries, such as Italy, France, Portugal, Finland and Greece.

It is important at this point to offer a brief description of the market power of stateowned enterprises and its evolution across countries. In many European countries the presence of the state in the economy stems from historical factors. After WWII, governments wished to intervene in the national economy by establishing public enterprises. These concerns resulted in a substantial presence of the state in a number of industrial, financial, and commercial sectors of the economy, in addition to health and education. ${ }^{9}$ In most of these countries the economic weight of these institutions did not change much during the 1980s and the early 1990s. Although a wave of privatization has been underway in Europe since the 1980s, this process was significative only in Germany and the U.K. In other European countries, such as France, Italy, and Spain, although discussion of the privatization of state-owned concerns started in the early 1980s, the bulk of privatization only began in

\footnotetext{
${ }^{8}$ Nicoletti, Scarpetta and Boylaud (1999) use this indicator, together with an index of interference in private firms that summarizes information about the government special voting rights, and use of command and control regulations, to build a summary index of State Control in the economy. See pp. 10-25 and Tables A2.1.1 to A2.1.5 in the Appendix. The latter is, in turn, part of the more general index of product market regulation.

${ }^{9}$ There are different historical motivations for the emergence and evolution of public enterprises in many European countries over the post-WWII period, for example, to provide basic services and infrastructure and to support the employment level in the economy. See Toninelli (2000) for an extensive account of this phenomenon in a selected number of countries (Italy, France, Germany, Spain, UK and the U.S.)
} 
the early 1990s. For instance, in Italy the state still owned four of Italy's top-ten corporate groups, and five of the top-ten individual businesses at the beginning of the 1990s. In 1996, the state still owned more than fifty percent of Italy's banks. Moreover, in the same year, the state still had a statutory or de facto monopoly over basic phone services, gas import and distribution, and cigarettes and tobacco. A similar picture emerges for Spain. In 1996, the total product of one of the three state holding companies accounted for more than $7 \%$ of Spain's GDP, and for about $10 \%$ of Spain's industrial production (including $100 \%$ in aluminum). ${ }^{10}$ It is important to note here that our model takes the existence of publicly operated enterprises as given. Although it is certainly interesting to explore how these institutions emerged, the scope of this paper is simply to emphasize how the existing institutions affect a country's employment outcomes. Moreover, as argued above, the extent of public ownership did not change substantially over our period of interest. This is also documented in the work by Alesina, Ardagna, Nicoletti and Schiantarelli (2003). They show that the index of public ownership remained constant in France, Italy and Spain between 1975 and the early 1990s. ${ }^{11}$

In the spirit of Ljungvist and Sargent (1998) we study the effect of an increase in turbulence in the economic environment since the 1970s on European unemployment. However, we employ a different mechanism. Whereas they focus on the role of unemployment insurance, we focus on the effect of state control and the role that the government plays as an employer. As a result of this difference in focus, we also model turbulence differently. Whereas they model it as an increase in the probability that that a worker loses his or her job, and therefore the skills associated with that job, we model it in a way that has wider scope, as a mean-preserving spread of the distribution of output.

The increase in economic turbulence has been interpreted in a context-dependent way, as an increase in the variability of a number of common aggregate shocks that hit the world economy, starting in the early 1970s, but more accurately, it may be interpreted as an increase in the variability in the occurrence and strength of a variety of possible shocks to the world economy.

We now focus on the particular aspects of turbulence to hit the world economy, beginning in the early 1970s. As argued in the 1994 OECD Job Study, the economic environment became more turbulent as a consequence of the two oil price shocks of the early 1970s and

\footnotetext{
${ }^{10}$ See Economist Intelligence Unit, Country Commerce Reports, several years.

${ }^{11}$ See Alesina, Ardagna, Nicoletti and Schiantarelli (2003), Figure 3. The indicator is computed for seven non-manufacturing industries: electricity and gas supply, road freight, air passenger transport, rail transport, post and telecommunications.
} 
of $1979 / 1980$, the increase in the volatility of exchange rates due to the abandonment of the Bretton Woods fixed exchange rate regime, and the waves of financial-market liberalization and product market deregulation in the 1980s. Pervasive technological change, and the trend toward globalization contributed to heighten this increase in turbulence even more. Gottschalk and Moffitt (1994) provide evidence of this increase in economic instability. In particular, they show that a large component of the widening of the earnings distribution in the U.S. labor market during the 1980s was due to a sharp increase in the earnings instability for individual workers. They show that one-third to a half of the increases in the variance of earnings from the 1970s to the 1980s can be attributed to transitory movements in earnings. More recently, Gottschalk and Moffitt (1998) used a formal model for earnings dynamics and concluded that the increase in the variance of the transitory component accounts for half of the total increase in the variance of individual male earnings over the period 1969-1991. A similar pattern has also been observed in other countries. Dickens (2000) concludes that the transitory component explains about half of the increase in earnings inequality in the U.K. between 1975 and 1995. Baker and Solon (2003) report evidence that the increase in the transitory component of earnings did also contribute to the increase in earnings inequality in Canada. Cappellari (2002) reports a similar increase for Italy between 1983 and 1994. Our assumption of a mean-preserving spread of the match-specific shock is meant to capture this increase in the instability of wages.

Next we document that, consistent with the predictions of our model, countries that experienced the largest growth in unemployment over the 1980s also had the largest increases in public sector employment. Figure 4.2 plots the change in unemployment rate between the early 1970s and the early 1990s against the change in public sector employment (expressed as a percentage of total employment) for the subset of OECD countries for which comparable time series data are available. Data on public employment in 1970 and in 1990 are from the OECD, Historical Statistics. Data on standardized unemployment rates are from Nickell, Nunziata, and Ochel (2002). They refer to the average standardized unemployment rate over the 1965-1972 and 1988-1995 time periods. ${ }^{12}$ The figures only include employment in the limited public sector, because data on employment in public enterprises in the 1970s are not available. Panel A reports the actual values for the percentage difference in unemployment rates and the percentage change in public employment rates between the two periods. Panel $\mathrm{B}$ presents data on the ranking of countries along the two dimensions. The figures show that there is a positive cross-country correlation between the two variables. The Spearman

\footnotetext{
${ }^{12}$ See Table 1 in Nickell, Nunziata and Ochel (2002) for the data sources. The authors use OECD standardized unemployment rates whenever possible.
} 
rank correlation between the two series is equal to 0.49 and is significant at the $5 \%$ level. It might be thought that this positive cross-country correlation is simply due to the fact that in some of these countries, aggregate employment declined disproportionately more and not by a genuine (relative) increase in the number of public sector employees. However, we find similar results when we measure public employment as a fraction of the labor force. In this case the Spearman rank correlation between the two series is equal to 0.40 and is significant at the $10 \%$ level. This is consistent with the prediction of our model that, for some parameters, overall unemployment and public employment increase simultaneously as the economy becomes more turbulent.

Additional evidence in favor of our model's predictions is provided by Nicoletti, et. al (2001), who show, in particular, that there is a negative correlation between the degree of public ownership and employment across countries and that countries characterized by a larger share of state ownership also experienced the lowest employment growth between 1982 and 1995. They find that the (simple) cross-country correlation between employment rate in 1995 (in the non-agricultural business sector) and the index of public ownership is equal to -0.71 and significant at the $10 \%$ level. Moreover, they also show that this index has a negative relationship with employment growth between 1982 and 1995 (-.44). ${ }^{13}$ Such a negative relationship is robust to the inclusion of other factors in the regression analysis. Further evidence of this negative relationship is provided by Algan, Cahuc, and Zylberberg (2002), who show how public employment may have a crowding out effect on total employment in those countries where the public goods produced are substitutes for private sector goods. This finding is consistent with ours as the goods produced by the two sectors are substitutes in the model.

A number of empirical studies support the finding that the earnings dispersion for the public sector is larger than that for the private sector. These studies examine how different sectors of employment affect different measures of the distribution of earnings for a subset of countries. They conclude that, in all countries considered, there exists a more compressed wage distribution in the public sector. ${ }^{14}$ Borjas (2002) documents that whereas U.S. wage inequality in the private sector widened substantially over the past two decades, the distribution in the public sector has remained relatively more stable He finds that the dispersion of the log weekly wage distribution for men in the private sector, as measured

\footnotetext{
${ }^{13}$ As a term of comparison, the index of employment protection legislation has a correlation of -0.61 with employment rate in 1995 and of -0.45 with the growth in employment rate between 1982 and 1995 .

${ }^{14}$ See Gregory and Borland (1999) for a review.
} 
by the 90 th to 10 th percentile, is equal to $1.3 \log$ points for 1975 when the corresponding figure for public sector employees is equal to 1.1. By 2000, inequality had increased to 1.7 in the private sector and 1.28 in the public sector. Gosling and Disney (1998) finds similar results for the U.K. over the period 1983 to the mid-1990s. The volatility of earnings in the public sector, as measured by the 90th to 10th percentile ratio of weekly earnings, increased from 2.82 to 2.86 , whereas the volatility in the private sector increased from 3.05 to 3.32 . Cappellari (2002) show that a similar pattern may also be observed in Italy. He also shows that between 1983 and 1994 the transitory component of earnings was almost zero in the public sector, whereas it was positive and increasing in the private sector. This is consistent with the evidence reported above for the increase in the volatility of earnings and provides additional support for our argument. In fact, our model predicts that following an increase in turbulence the volatility in the public sector is unchanged, whereas it increases in the private sector. Finally, an empirical study by Jurges (2002) documents that in Germany, the wage distribution in the public sector is generally less dispersed than in the private sector.

To conclude, we see this paper as a simple theoretical contribution to the literature that tries to explain the large and persistent increase in European unemployment between the 1970s and the 1990s. In particular, we develop a model that provides insights into one possible mechanism through which the presence of a very active government in the economy may affect its labor market performance. We also present suggestive empirical evidence that shows that such a mechanism may have contributed to the increase in European unemployment over this time period.

\section{References}

[1] Alesina, A., Ardagna S., Nicoletti G. and F. Schiantarelli (2003), "Regulation and Investment," NBER Working Paper \#9560.

[2] Algan, Y. Cahuc, P. and Zylberberg A. (2002), "Public Employment and Labor Market Performance," CEPR, Economic Policy.

[3] Baker, M. and Solon, G. (2003), "Earnings Dynamics and Inequality among Canadian Men, 1976-1992: Evidence from Longitudinal Income Tax Records," Journal of Labor Economics, 21(2): 289-321.

[4] Bentolila, S. and Bertola, G. (1990), "Firing costs and labour demand: how bad is eurosclerosis?," The Review of Economic Studies 57: 381-402. 
[5] Bertola, G. and Ichino, A. (1995), "Wage inequality and unemployment: United States v.s. Europe," NBER Macroeconomics Annual: 13-54.

[6] Bertola, G. and Rogerson, R. (1997), "Institutions and labor reallocation," European Economic Review 41: 1147-1171.

[7] Blanchard, O. and Giavazzi F. (2003), "Macroeconomic Effects of Regulation and Deregulation in Goods and Labor Market," Quarterly Journal of Economics (forthcoming).

[8] Blanchard, O. and Philippon T. (2003), "The decline of rents, and the rise and fall of European unemployment," MIT, mimeo.

[9] Blanchard, O. and Wolfers, J. (2000), "The Role of Shocks and Institutions in the Rise of European Unemployment: The Aggregate Evidence," Economic Journal, 110, March, C 1 - 33.

[10] Borjas, G. J. (2002), "The Wage Structure and the Sorting of Workers into the Public Sector," NBER Working Paper \# 9313.

[11] Bruno, M. and J. D. Sachs (1985), Economics of Worldwide Stagflation, Cambridge, Massachusetts: Harvard University Press.

[12] Cappellari, L. (2002) "Earning Dynamics and Uncertainty in Italy: How Do they Differ Between the Private and the Public Sectors?," Labour Economics, , 9 (4):. 477-496

[13] Dickens, R. (2000), "The Evolution of Individual Male Earnings in Great Britain: 1975-95," Economic Journal, 110 (460).

[14] Disney, R. and Gosling A. "Does It Pay to Work in the Public Sector?," Institute for Fiscal Studies: Fiscal Studies, 19 (4): 347-374.

[15] Ebell, M. and Haefke C. (2002) "Product Market Deregulation and Labor Market Outcomes," Swiss National Bank, Study Center Gerzensee, WP\# 02.08.

[16] Gregory, G. R. and Borland J. (1999), "Recent Developments in Public Sector Labor Markets," in O. Ashenfelter and D. Card, eds., Handbook of Labor Economics, Vol. 3, Elsevier Science B.V., 3573-3630.

[17] Hall, R. E. (1975), "The Rigidity of Wages and the Persistence of Unemployment," Brookings Papers on Economic Activity, 1975, No. 2: 301-335. 
[18] Hosios, A.J. (1990), "On the Efficiency of Matching and Related Models of Search and Unemployment," Review of Economic Studies 57:279-98.

[19] Jürges, H. (2002), "The Distribution of the German Public-Private Wage Gap," Labour, 16 (2): $347-381$.

[20] Layard, R., Nickell S., and Jackman J (1991), Unemployment, Oxford University Press.

[21] Ljunqvist, L. and Sargent, T. (1998), "The European unemployment dilemma," Journal of Political Economy 106: 514-550.

[22] Marimon, R. and Zilibotti, F. (1999), "Unemployment vs. mismatch of talent: reconsidering unemployment benefits," The Economic Journal, 109: 266-91.

[23] Mortensen, D. and Pissarides, C. (1999a), "Unemployment responses to 'skill-biased' technology shocks: the role of labour market policy," The Economic Journal, 109: 242-265.

[24] Mortensen, D. and Pissarides, C. (1999b), "Job reallocation employment fluctuations and unemployment." Handbook of Macroeconomics Chapter 18.

[25] Nickell, S., L. Nunziata, and W. Ochel (2002), "Unemployment in the OECD since the 1960s. What do we know?," Bank of England.

[26] Nickell, S. (1997), "Unemployment and Labor Market Rigidities: Europe versus North America," Journal of Economic Perspectives, 11: 55-74.

[27] Nicoletti, G. Scarpetta, S. and Boylaud, O. (1999), "Summary Indicators of Product Market Regulation with an Extension to Employment Protection Legislation," OECD, Economics Department WP 226.

[28] Nicoletti, G. Haffner, R. C. G. Nickell, S. Scarpetta, S. and Zoega, G. (2001). "European Integration, Liberalization, and Labor Market Performance," in Welfare and Employment in a United Europe, Bertola G., Boeri T., and Nicoletti G. eds., MIT Press/Fondazione Rodolfo Debenedetti.

[29] OECD (2001), Historical Statistics.

[30] OECD (1997), "Measuring Public Employment in OECD Countries: Sources, Methods and Results", OECD Report.

[31] OECD (1994), The OECD Jobs Study, Facts, Analysis, and Strategies, Part I. 
[32] Phelps, E.S. (1994), Structural Slumps, Cambridge, MA: Harvard University Press.

[33] Pissarides, C. (2000), Equilibrium Unemployment Theory, second edition, MIT Press, Cambridge, MA.

[34] Rodrik, D. (1997), "What Drives Public Employment?," NBER Working Paper \# 6141, forthcoming in Review of Development Economics.

[35] The Economist Intelligence Unit (1996-2001), Country Commerce Reports.

[36] Toninelli, P. (2000), The Rise and Fall of State-Owned Enterprises in the Western World, Cambridge University Press, Cambridge, UK. 
Table 4.1: Employment in the "limited" public sector and in public enterprises (percentage of total employment)

\begin{tabular}{lcc}
\hline & $\begin{array}{c}\text { Employment in } \\
\text { Public Sector }\end{array}$ & $\begin{array}{c}\text { Employment in } \\
\text { Public Enterprises }\end{array}$ \\
\hline \hline Australia & 14.6 & 4.1 \\
Austria & 15.8 & 6.7 \\
Belgium & 20 & 3.9 \\
Canada & 17.4 & 2.5 \\
Denmark & 35.4 & 3.9 \\
Finland & 25.1 & 2.1 \\
France & 20.2 & 6.8 \\
Germany & 14.1 & 1.3 \\
Greece & 9.6 & 3.3 \\
Ireland & 16.8 & 4.3 \\
Italy & 18.2 & 5 \\
Japan & 6.5 & 0.5 \\
Netherlands & 11.8 & 2.1 \\
New Zealand & 12.1 & 2.1 \\
Portugal & 14.8 & 2.7 \\
Spain & 15.1 & 2.9 \\
Sweden & 31.7 & 6.4 \\
Turkey & 9.4 & 2.7 \\
United Kingdom & 11.9 & 5 \\
United States & 14.2 & 0.7 \\
\hline \hline
\end{tabular}

Data Source: "Measuring Public Employment in OECD Countries:

Sources, Methods, and Results", OECD Report 1997 


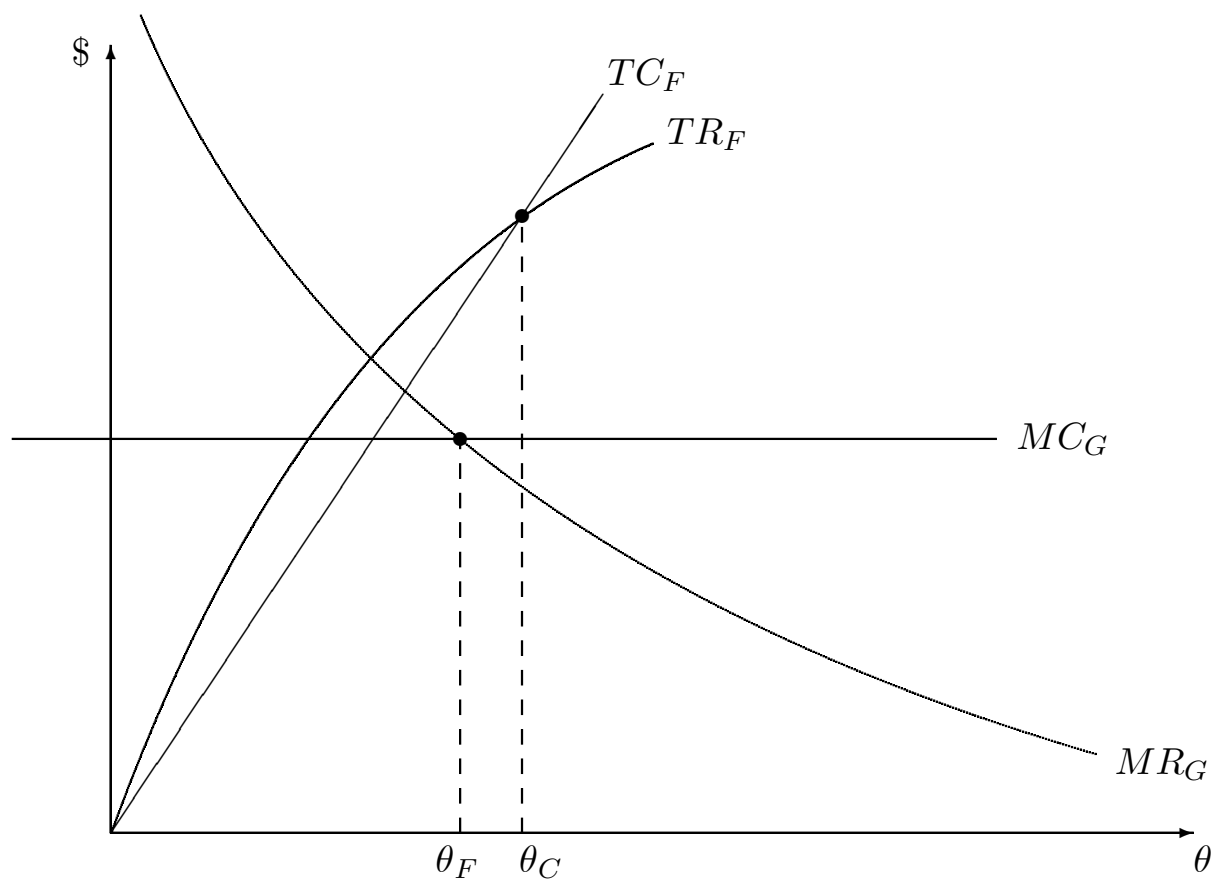

Figure 2.1.: Cost and Revenue Curves (per worker) 


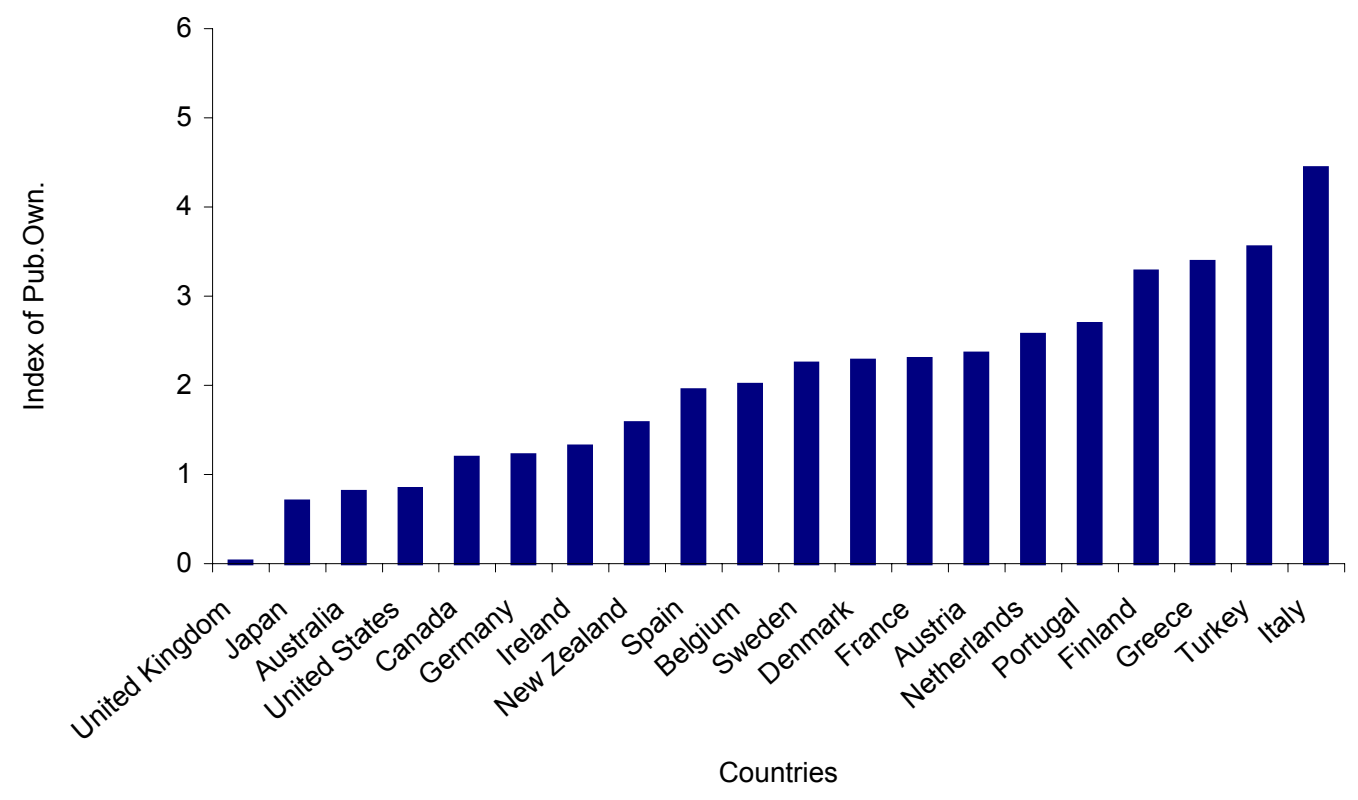

Figure 4.1: Cross-country differences in Public Ownership 
Panel A: Values (in percentage)

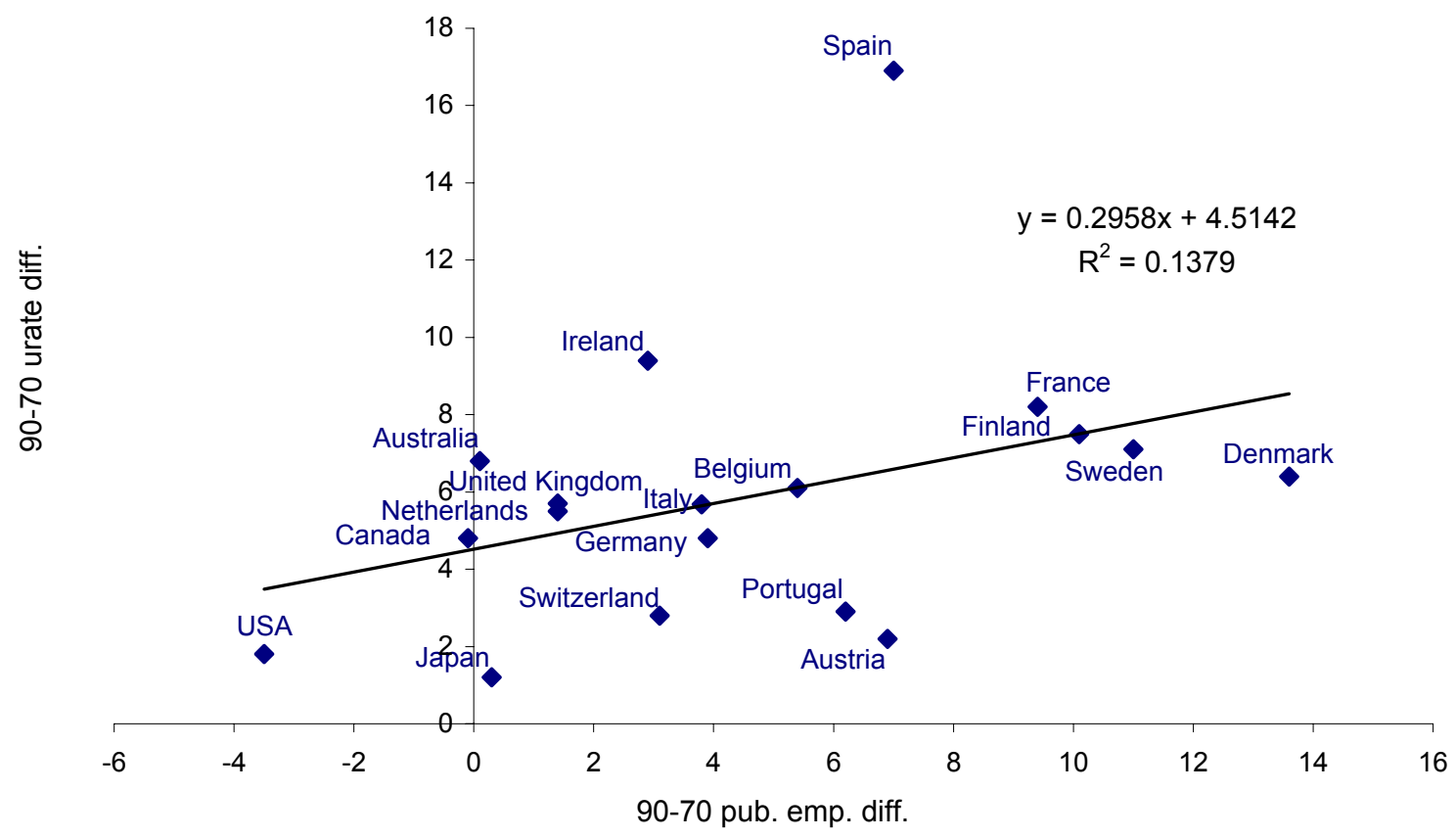

Panel B: Cross country rankings

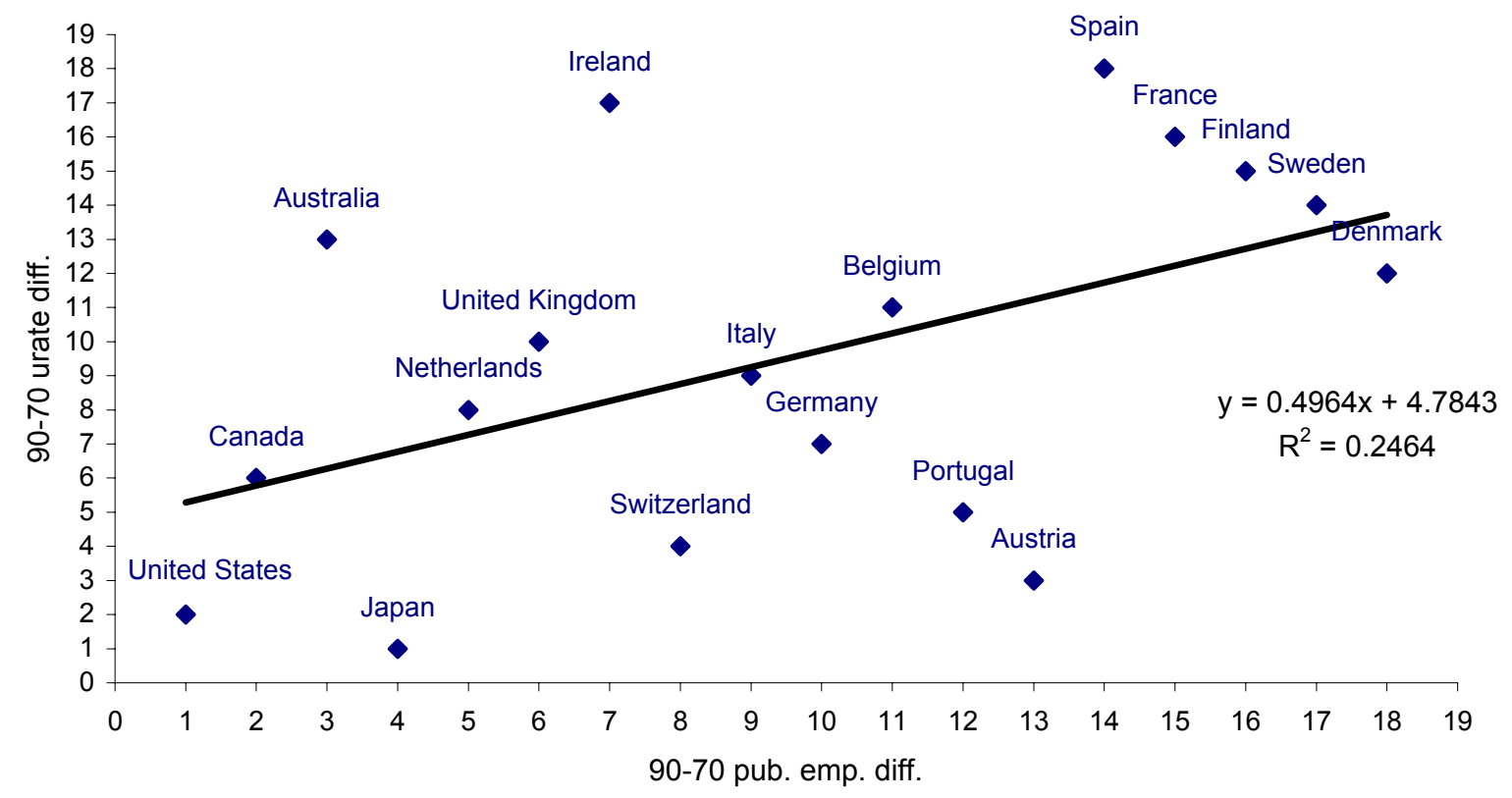

Figure 4.2: Percentage Differences in Public Employment and in Unemployment, 1970-1990 


\section{Appendix: The model with a general utility specification}

Assume that the utility function $U: \mathbb{R}_{++}^{2} \rightarrow \mathbb{R}$ is smooth, jointly strictly concave and strictly increasing in both parameters. Job-searchers and vacancies in both sectors are matched through an homogenous of degree one matching function. That is, in each sector $i=1,2$ the number of matches $M_{i}$ can be written as $A_{i} u_{i}^{\gamma_{i}} v_{i}^{1-\gamma_{i}}, \gamma_{i} \in(0,1)$ where $u_{i}$ is the measure of searchers in sector $i$ while $v_{i}$ is the measure of vacancies posted in sector $i$. This parametric assumption is hereafter referred to as CD. Let $\gamma_{i}=\gamma, i=1,2$, just as $A_{i}=A, i=1,2, Y_{i}=Y$ a.s., $i=1,2$, and $\alpha_{i}=\alpha, i=1,2$, where $Y_{i}$ is (the distribution of) the output in sector $i$ of a firm (identified with the output of a match) and $\alpha_{i} \in(0,1)$ is the share of realized output given to the worker. $A$ is a parameter that is small enough so as to guarantee that matching probabilities for searchers and vacancies are well-defined. That is, the production technologies are the same across sectors, an assumption hereafter referred to as IT. The cost of opening a vacancy is $R>0$. The market tightness in sector $i=1,2$, is the ratio of vacancies to searchers in that sector: $\theta_{i}=v_{i} / u_{i}$. We denote the proportional tax rate by $\tau$, the relative price of good 1 by $p$, the wage in sector $i=1,2$ by $w_{i}$ and the unemployment benefit by $w_{0}$. Superscripts $B$ and $E$ refer to the benchmark and the European economy, respectively.

The proof goes as follows. Lemma 1 establishes that the relative price of good 1 in the benchmark economy is 1 . This implies that comparing employment rates $E^{B}$ and $E^{E}$ between the two economies boils down to comparing the market tightness of the first sector across economies (Lemma 2). Lemma 3 shows that workers are completely "insured" in Europe, that is, workers are indifferent between being unemployed and working in either sector. Using this result, Lemma 4 determines the values of the relevant market tightnesses. In what follows, ZP refers to the zero profit condition in the private sector(s) and LI (labor indifference) refers to the restriction that searchers are indifferent across sectors.

The next lemma shows that CD and IT imply that the relative price in the U.S. economy is 1 .

Lemma $6 p^{S}=1$.

Proof. Let $p$ stand for $p^{B}$ in what follows in this proof. From the zero profit condition (hereafter ZP) and CD, we get that:

$$
\frac{\theta_{1}}{\theta_{2}}=p^{1 / \gamma}
$$

Therefore, because searchers are indifferent across sectors (hereafter LI):

$$
p^{\frac{1-\gamma}{\gamma}}\left[E v((1-\tau) \alpha p Y, p)-v\left((1-\tau) w_{0}, p\right)\right]=\left[E v((1-\tau) \alpha Y, p)-v\left((1-\tau) w_{0}, p\right)\right],
$$


where $v(\cdot)$ is the consumer's indirect utility function. If the R.H.S. is zero, then so must be the L.H.S., so that

$$
E v((1-\tau) \alpha p Y, p)=v\left((1-\tau) w_{0}, p\right)=E v((1-\tau) \alpha Y, p),
$$

and therefore $p=1$. If the L.H.S. is nonzero, then the right hand side is not either. In particular, both must be strictly positive for workers to actively search. Notice then that for $p>1, p^{\frac{1-\gamma}{\gamma}}>1$ and $E v((1-\tau) \alpha p Y, p)>E v((1-\tau) \alpha Y, p)$ imply that the equality cannot hold, and a similar reasoning applies for $p<1$. The equality trivially holding for $p=1$ therefore implies that this is the unique solution.

The second lemma shows that CD and IT imply that comparing (un)employment rates boils down to comparing market tightnesses of the first sector across economies.

Lemma $7 E^{E}>E^{S}$ iff $\theta_{1}^{S}>\theta_{2}^{E}$

Proof. Observe that total employment $E$ satisfies:

$$
\begin{aligned}
E & =M_{1}+M_{2} \\
& =\phi\left(\theta_{2}\right)+u_{1}\left(\phi\left(\theta_{1}\right)-\phi\left(\theta_{2}\right)\right),
\end{aligned}
$$

where $\phi(\theta)$ is the probability that a job searcher is matched with a vacancy given market tightness $\theta$. So

$$
E^{E}-E^{B}=u_{1}^{E}\left(\phi\left(\theta_{1}^{E}\right)-\phi\left(\theta_{2}^{E}\right)\right),
$$

since $\theta_{1}^{B}=\theta_{2}^{B}=\theta_{2}^{E}$ by ZP.

The remainder of the appendix focuses on the European economy and superscripts are accordingly dropped. The next lemma shows that the wage in the public sector is the certainty equivalent of the (risky) wage in the private sector, and that the unemployment benefit completely insures searchers. ${ }^{15}$ Because the government is risk-neutral and workers are risk-averse, the optimal unemployment benefits and public wage are fixed numbers rather than lotteries. Similarly, the government can always decrease the spread between this public wage and the unemployment benefit in a way that both increases welfare and decreases the government's expenditures. (However, the proof is a little more involved than this intuition suggests, because it is typically not possible to only change those two variables while keeping searchers indifferent across sectors).

\footnotetext{
${ }^{15}$ Note that introducing a disutility of working merely amounts to introducing a wedge between the unemployment benefit and the certainty equivalent of the wage in either sector, without changing the full insurance result.
} 
Lemma 8 For given $p$ and $\tau, w_{0}=w_{1}=w$, where $\operatorname{Ev}\left((1-\tau) w_{2}, p\right)=v((1-\tau) w, p)$

Proof. Fix $p>0$ throughout and let $\omega_{i}=(1-\tau) w_{i} i=0,1,2$. For sake of contradiction suppose not, that is $w_{0}<w_{1}$ and therefore $w_{0}<w$ (by LI). Without loss of generality (we reverse the role of indices in what follows otherwise) we assume that:

$$
\frac{M_{1} v_{p}\left(\omega_{1}, p\right)+\left(u_{1}-M_{1}\right) v_{p}\left(\omega_{0}, p\right)}{u_{1}} \geq \frac{M_{2} E\left[v_{p}\left(\omega_{2}, p\right)\right]+\left(u_{2}-M_{2}\right) v_{p}\left(\omega_{0}, p\right)}{u_{2}},
$$

where $v_{w}$ and $v_{p}$ are the derivatives of $v$ with respect to $w$ and $p$. Define then $\frac{\Delta \omega_{1}}{\Delta}$ such that :

$$
\frac{M_{1}}{u_{1}} v_{w}\left(\omega_{1}, p\right) \frac{\Delta \omega_{1}}{\Delta}+\frac{\left(u_{1}-M_{1}\right)}{u_{1}} v_{w}\left(\omega_{0}, p\right)=0 .
$$

Then given that $v$ is strictly concave we have that:

$$
\frac{M_{1}}{u_{1}} \frac{\Delta \omega_{1}}{\Delta}+\frac{\left(u_{1}-M_{1}\right)}{u_{1}}<0
$$

Next, for $\frac{\Delta p}{\Delta}<0$, define $\frac{\Delta \omega_{2}}{\Delta}$ such that :

$$
\begin{aligned}
& \frac{M_{1}}{u_{1}} v_{w}\left(\omega_{1}, p\right) \frac{\Delta \omega_{1}}{\Delta}+\frac{\left(u_{1}-M_{1}\right)}{u_{1}} v_{w}\left(\omega_{0}, p\right) \\
& +\left(\frac{M_{1} v_{p}\left(\omega_{1}, p\right)+\left(u_{1}-M_{1}\right) v_{p}\left(\omega_{0}, p\right)}{u_{1}}\right) \frac{\Delta p}{\Delta} \\
= & \frac{M_{2}}{u_{2}} E\left[v_{w}\left(\omega_{2}, p\right)\right] \frac{\Delta \omega_{2}}{\Delta}+\frac{\left(u_{2}-M_{2}\right)}{u_{2}} v_{w}\left(\omega_{0}, p\right) \\
& +\left(\frac{M_{2} E\left[v_{p}\left(\omega_{2}, p\right)\right]+\left(u_{2}-M_{2}\right) v_{p}\left(\omega_{0}, p\right)}{u_{2}}\right) \frac{\Delta p}{\Delta} .
\end{aligned}
$$

Notice that Government controls the random variable $\omega_{2}$ downwards through the tax rate $\tau$. Since by assumption the last term on the L.H.S. is smaller than the last term on the R.H.S., and the first terms on the L.H.S. sum to zero it must be that:

$$
\frac{M_{2}}{u_{2}} E\left[v_{w}\left(\omega_{2}, p\right)\right] \frac{\Delta \omega_{2}}{\Delta}+\frac{\left(u_{2}-M_{2}\right)}{u_{2}} v_{w}\left(\omega_{0}, p\right)<0 .
$$

Then given that $v$ is strictly concave we have that:

$$
\frac{M_{2}}{u_{2}} \frac{\Delta \omega_{2}}{\Delta}+\frac{\left(u_{2}-M_{2}\right)}{u_{2}}<0
$$

Define finally $\frac{\Delta p}{\Delta}$ by:

$$
\frac{M_{1}}{u_{1}} \frac{\Delta \omega_{1}}{\Delta}+\frac{\left(u_{1}-M_{1}\right)}{u_{1}}+\frac{M_{2}}{u_{2}} \frac{\Delta \omega_{2}}{\Delta}+\frac{\left(v_{2}-M_{2}\right)}{u_{2}}=M_{1} Y \frac{\Delta p}{\Delta},
$$


and observe that by construction it is indeed negative. To conclude the proof it remains to observe that by Taylor's theorem there exists a sufficiently small $\Delta>0$ in the net unemployment benefits $\omega_{0}$ and corresponding changes $\Delta p, \Delta \omega_{1}$, and $\Delta \omega_{2}$ such that LI and Budget Balance (hereafter, BB) are maintained while welfare increases. $(*),(* *)$, and $(* * *)$ imply that worker searching in sector 1 are better off from the change, and $(* *)$ implies that LI is maintained (which in turn implies that workers searching in sector 2 are also better off). Finally, $(* * *)$ implies that the budget remains balanced.

The final lemma provides closed-form solutions for the two relevant market tightnesses. The market tightness for the public sector is slightly more complicated to determine than for the private sector. The idea is as follows. Given the relative price of good 1, the gross income of a worker in the private sector is determined, and cannot be influenced by the government. This gross income pins also down the gross income of unemployed workers and of workers in the public sector, given the previous lemma. Given a relative price and the consumer's gross income, the indirect utility function of a consumer decreases in the tax rate. Therefore, to maximize welfare, for a given relative price, the government should minimize the tax rate. In particular, this implies that, at the optimum, the government cannot, by changing $u_{1}$ or $v_{1}$, increase its surplus, for otherwise it could have chosen a lower tax rate. Therefore, holding the price fixed, the derivatives with respect to $u_{1}$ and $v_{1}$ of the budget surplus should be zero, which, along with budget balance, pins down the market tightness. However, the price may change as $u_{1}$ and $v_{1}$ change, and this price change has two effects on welfare: one positive, because it is likely to decrease the relative price of good 1, one negative, because to offset this loss in budget revenue, the government needs to increase the tax rate to balance the budget. If consumer's utility function displays constant elasticity of substitution between the two goods, these two effects cancel each other.

Lemma $9 \theta_{1}=\frac{1-\gamma}{\gamma} \frac{w}{R} \pm \sigma$, and $\theta_{2}=\left(\frac{A(1-\alpha) Y}{R}\right)^{1 / \gamma}$, where $\sigma=0$ with constant elasticity of substitution.

Proof. $\quad \theta_{2}$ is easily found from ZP. Using the previous lemma, we write $w_{0}, w_{1}$ and $w$ interchangeably. Observe that the government can dissipate any surplus without changing the price by increasing sufficiently the net unemployment benefits $\omega_{0}$ and reducing the tax rate in the amount necessary to maintain labor indifference. Such a change would unambiguously improve welfare. As a consequence, at the optimum, the government cannot change $u_{1}$ nor $v_{1}$ in such a way as to create a surplus (Notice that $u_{1}$ and $v_{1}$ do not affect welfare directly). Therefore, if we write $\mathrm{BB}$ as $f\left(u_{1}, v_{1}\right)=0$ for some $f$, it must be that $\frac{d f\left(u_{1}, v_{1}\right)}{d u_{1}}=0$ and $\frac{d f\left(u_{1}, v_{1}\right)}{d v_{1}}=0$ at the optimal values $\left(u_{1}, v_{1}\right)$. Holding the price fixed, we 
have therefore:

$$
\left(1-M_{2}\right)(1-\tau) w+(1-\tau) R v_{1}=p M_{1} Y+\frac{\tau}{1-\alpha} R v_{2}
$$

where $M_{2}=\left(1-u_{1}\right) A \theta_{2}^{1-\gamma}, M_{1}=u_{1} A \theta_{1}^{1-\gamma}, u_{2}=\left(1-u_{1}\right) \theta_{2}$ (We used ZP to rewrite budget balance). In addition:

$$
\begin{aligned}
p M_{1} Y & =\frac{(1-\tau) R v_{1}}{1-\gamma} \\
(1-\tau) M_{2} w & =\gamma p M_{1} Y \frac{1-u_{1}}{u_{1}}-\frac{\tau R v_{2}}{1-\alpha} .
\end{aligned}
$$

Substituting back into the budget constraint yields that $\theta_{1}=\frac{1-\gamma}{\gamma} \frac{w}{R}$. Changing $u_{1}$ and $v_{1}$ may affect the price however, which affects both the welfare (the consumer's indirect utility function is decreasing the price) directly, and indirectly through the tax rate that adjusts to balance the budget. We summarize this effect by $\sigma$, which may be either positive or negative. When the utility function exhibits constant elasticity of substitution, it is straightforward to compute the optimal choices and verify that $\sigma=0$. 


\section{CENTRE FOR ECONOMIC PERFORMANCE \\ Recent Discussion Papers}

609 Nikolaus Wolf

608 Ellen E. Meade

David Stasavage

607 Ghazala Azmat

Maia Güell

Alan Manning

606 Henry G. Overman

L. Alan Winters

605 Stephen Machin

Stephen Wood

604 Maarten Goos

Alan Manning

603 Nan-Kuang Chen

Hsiao-Lei Chu

602 Ricardo Peccei

Helen Bewley

Howard Gospel

Paul Willman

601 Andy Charlwood

600 Christopher A. Pissarides

599 Stephen Bond

Dietmar Harhoff

John Van Reenen

598 Michael Storper

Anthony J. Venables
Endowments, Market Potential, and Industrial

Location: Evidence from Interwar Poland

(1918-1939)

Publicity of Debate and the Incentive to Dissent:

Evidence from the US Federal Reserve

Gender Gaps in Unemployment Rates in OECD

Countries

The Geography of UK International Trade

Looking for HRM/Union Substitution: Evidence from British Workplaces

Lousy and Lovely Jobs: the Rising Polarization of Work in Britain

Collateral Value and Forbearance Lending

Is it Good To Talk? Information Disclosure and Organisational Performance in the UK

Incorporating evidence submitted on the DTI discussion paper 'High Performance Workplaces Informing and Consulting Employees'

The Anatomy of Union Decline in Britain 1990-1998

Unemployment in Britain: A European Success Story

Corporate R\&D and Productivity in Germany and the United Kingdom

Buzz: Face-to-Face Contact and the Urban Economy 
597 Stephen Gibbons

Alan Manning

596 Paul Gregg

Maria Gutiérrez-

Domènech

Jane Waldfogel

595 Stephen Bond

Dietmar Harhoff

John Van Reenen

594 Andrew B. Bernard

Stephen Redding

Peter K. Schott

593 Anthony J. Venables

592 Sylvie Charlot

Gilles Duranton

591 Paul Willman

Alex Bryson

Rafael Gomez

590 Marco Manacorda

589 Alex Bryson

Rafael Gomez

588 Henry G. Overman

L. Alan Winters

587 Pierre-Philippe Combes

Henry G. Overman

586 Henry G. Overman
The Incidence of UK Housing Benefit: Evidence from the 1990s Reforms

The Employment of Married Mothers in Great

Britain: 1974-2000

Investment, R\&D and Financial Constraints in Britain and Germany

Product Choice and Product Switching

Spatial Disparities in Developing Countries: Cities, Regions and International Trade

Communication Externalities in Cities

Why Do Voice Regimes Differ?

Child Labor and the Labor Supply of Other

Household Members: Evidence from 1920 America

Why Have Workers Stopped Joining Unions?

Trade Shocks and Industrial Location: the Impact of EEC Accession on the UK

The Spatial Distribution of Economic Activities in the European Union

Can We Learn Anything from Economic Geography Proper?

The Centre for Economic Performance Publications Unit

Tel 02079557673 Fax 02079557595 Email info@cep.lse.ac.uk Web site http://cep.lse.ac.uk 